\title{
ELABORAÇÃO DE ROTEIRO PARA UMA TRILHA INTERPRETATIVA NO PARQUE NATURAL MORRO DO OSSO, PORTO ALEGRE (RS)
}

Patricia da Costa Gonçalves ${ }^{1}$

Celson Roberto Canto-Silva ${ }^{2}$

Resumo: A Educação Ambiental constitui-se numa importante estratégia para o planejamento, fortalecimento e gestão das unidades de conservação (UC). A despeito disso, no Brasil, a inserção das UCs como temática na Educação Ambiental formal e não formal ainda é limitada. Assim, iniciativas que busquem reverter esse panorama são fundamentais. Este trabalho teve como objetivo elaborar um roteiro para uma trilha interpretativa no Parque Natural Morro do Osso, localizado no município de Porto Alegre, RS. Para tal, foram utilizadas metodologias para a seleção e avaliação do potencial dos pontos interpretativos e para a elaboração de atividades. Foram estabelecidos seis pontos e propostas 12 atividades adaptadas ao público-alvo.

Palavras-chave: Interpretação Ambiental; Roteiro Interpretativo; Trilha Interpretativa; Educação Ambiental.

\footnotetext{
${ }^{1}$ Instituto Federal de Educação, Ciência e Tecnologia do Rio Grande do Sul. E-mail: patriciacostag@gmail.com

2Instituto Federal de Educação, Ciência e Tecnologia do Rio Grande do Sul.

E-mail: celson.silva@poa.ifrs.edu.br
} 


\section{Introdução}

Assim como outros elementos, a biodiversidade é um componente fundamental para a manutenção das funções ecossistêmicas e, com isso, dos recursos e serviços ambientais que suportam todas as formas de vida e podem dar sustentabilidade ecológica, econômica e sociocultural ao homem (PRIMACK; RODRIGUES, 2001). A despeito disso, vivemos uma crise sem precedentes de perda da biodiversidade, resultante principalmente da atuação humana sobre os ecossistemas (WILSON, 2002; GANEM, 2010). Nesse contexto, o estabelecimento de áreas protegidas, porções do território separadas e com uso da terra e dos recursos naturais limitados, é de extrema relevância para a manutenção desses ambientes e, por isso, tem se tornado o principal instrumento de conservação da biodiversidade (BENSUSAN, 2006).

No Brasil, a Lei n. 9985, de 18 de julho de 2000, instituiu o Sistema Nacional de Unidades de Conservação (SNUC), constituído pelo conjunto das unidades de conservação (UCs) federais, estaduais e municipais (BRASIL, 2000). Segundo o SNUC, unidade de conservação é conceituada como:

[...] espaço territorial e seus recursos ambientais, incluindo as águas jurisdicionais, com características naturais relevantes, legalmente instituído pelo Poder Público, com objetivos de conservação e limites definidos, sob regime especial de administração, ao qual se aplicam garantias adequadas de proteção (BRASIL, 2000).

A despeito da grande variedade de estratégias de $E A$ empregadas nas UCs, como vivências na natureza (MENDONÇA, 2007; HIRATA; MOURA; SOUZA, 2013) e atividades experimentais (PERALTA, 2002; CHAGAS, 2005; SILVA et al., 2010), a Interpretação Ambiental (IA) é uma das mais frequentes (VASCONCELLOS, 1997; MENGHINI, 2005; SILVA; JÚNIOR, 2010).

Diversas são as definições para IA. Entretanto, a mais difundida é aquela proposta por Freeman Tilden, considerado o precursor da atividade. Segundo Tilden (1977, apud VASCONCELLOS, 2006), a IA é uma atividade educativa, que busca mostrar os significados e relações do ambiente por meio de experimentos e ilustrações. Ela traz às pessoas um mundo diferente, fazendo-as compreenderem o ambiente ao seu entorno através de vivências e não somente de informação.

Com base nos princípios propostos por Tilden e complementados por Beck e Cable (1998), a IA deve ser uma combinação de várias abordagens, que utilizam todos os sentidos para que de fato haja uma aprendizagem, trazendo possibilidades para a reflexão. Somam-se a isso as informações, cujo objetivo é despertar o interesse por situações inimagináveis. Ou seja, como conclui Ham (1992), a abordagem interpretativa deve ser amena (entreter), pertinente (com 
significado e apelo pessoal), organizada (não requerer muito esforço da audiência) e temática (trazer um tema, uma mensagem a ser compreendida). Importante ainda registrar que a IA pode dispor de um leque de inovações em relação aos meios e técnicas de comunicação e informação e que quando dirigida a crianças não pode ser apenas uma diluição da apresentação para adultos, mas adotar uma abordagem e um método fundamentalmente diferente.

Segundo Morales (1992, apud VASCONCELLOS, 2006), as trilhas guiadas, nas quais um intérprete conduz um grupo de pessoas através de um caminho, com pontos de parada pré-definidos, sendo desenvolvido um tema, são um dos meios interpretativos mais utilizados nos Parques da América Latina, assim como são consideradas, também, um dos meios mais eficazes. A respeito das trilhas interpretativas, Vasconcellos (2006) pontua:

[...] traduzem para o visitante os fatos que estão além das aparências (leis naturais, interações, história, cultura) ou fatos aparentes que não são comumente percebidos (singularidades, detalhes, vestígios, entre outros) [...] (VASCONCELLOS, 2006, p.46)

De acordo com Vasconcellos (2006), um programa interpretativo deve ser constituído por um conjunto de estratégias planejadas e desenvolvidas para cumprir um determinado objetivo. Da mesma forma, o planejamento de uma trilha interpretativa guiada também deve ser produto de uma planificação.

Os passos básicos para o planejamento de um programa interpretativo eficaz são sugeridos por diversos autores (SHARPE, 1982, apud NASCIMENTO, 2004; HAM, 1992; VASCONCELLOS, 1998; DIETZ; TAMAIO, 2000). Segundo Sharpe (1982, apud NASCIMENTO, 2004), o planejamento deve ser constituído por um conjunto de sete passos, nos quais, após a definição dos objetivos, grande ênfase é dada para a análise das oportunidades interpretativas. São os passos: determinação dos objetivos; inventário interpretativo; análise das oportunidades interpretativas; síntese; desenvolvimento do plano; implementação do plano; revisão e avaliação do plano.

Por sua vez, Vasconcellos (1998) propõe um planejamento a partir de seis passos, nos quais a identificação das oportunidades e necessidades da área, assim como do público-alvo, são fundamentais. São eles: identificação das oportunidades e necessidades; identificação do público alvo; identificação dos objetivos ou resultados esperados para cada público; escolha do tema ou mensagem; seleção das atividades, meios, métodos e técnicas (estratégias) a serem utilizados na transmissão das mensagens; e avaliação dos resultados e reformulação do programa, caso necessário.

Ambos enfoques sobre 0 planejamento interpretativo são complementares, de modo que, embora o cerne do planejamento do programa 
ou trilha resida na determinação das oportunidades interpretativas, estas, por sua vez, devem resultar do conhecimento da área a ser interpretada, da identificação e conhecimento do público-alvo e de um levantamento cuidadoso das várias técnicas de comunicação disponíveis (VASCONCELLOS, 2006).

O Parque Natural Morro do Osso (PNMO), localizado na porção sudoeste do município de Porto Alegre, RS, região em elevado processo de expansão urbana, constitui-se numa área protegida muito adequada para o desenvolvimento de atividades de EA formal e não formal, em vista do seu fácil acesso, por apresentar uma diversidade de públicos em seu entorno e por possuir equipe gestora capacitada para o atendimento dos visitantes. Trata-se de um fragmento natural constituído por formações florestais sob influência da Mata Atlântica e por campos rupestres, apresentando uma elevada biodiversidade, além de áreas de grande beleza cênica, muito utilizadas pela comunidade do entorno para o contato com a natureza (SESTREN-BASTOS, 2006).

Em seu Programa de Uso Público, o Plano de Manejo do PNMO prevê, para as atividades interpretativas, palestras e trilhas orientadas para grupos agendados, sendo estabelecidas em sua Zona de Uso Extensivo duas trilhas: "Trilha da Fonte" e "Trilha de Baixo". A trilha conhecida como Trilha de Baixo, embora utilizada na fase inicial do Parque para atividades de IA, em face do pouco uso posterior ainda carece da definição de um roteiro. É fundamental o estabelecimento deste roteiro em face das demandas atuais da gestão do Parque de utilização da trilha para grupos de escolares de menor idade. Justifica-se, portanto, a realização de um estudo que se detenha sobre essa demanda e apresente uma proposta de roteiro aos gestores, com base nos resultados obtidos.

Assim, buscando contribuir para a implementação dos objetivos do SNUC e considerando as demandas atuais da gestão do PNMO, o presente trabalho teve por objetivo elaborar um roteiro interpretativo para a Trilha de Baixo, propondo também uma metodologia para a construção desse planejamento.

\section{Procedimentos metodológicos}

A metodologia adotada no presente trabalho foi uma adaptação das metodologias propostas por Sharpe (1982, apud NASCIMENTO, 2004) e Vasconcellos (1998), na qual o planejamento do roteiro interpretativo da trilha foi constituído por seis etapas, assim ordenadas: (1) identificação das oportunidades e necessidades do Parque; (2) identificação do público-alvo; (3) definição dos objetivos e do tema; (4) realização do inventário interpretativo; (5) análise das oportunidades interpretativas e (6) seleção das estratégias interpretativas e proposição do roteiro. 


\section{Identificação das oportunidades e necessidades do Parque}

Para identificar as oportunidades e necessidades do Parque, buscou-se estabelecer contato com a equipe gestora do mesmo, sendo realizados diversos encontros com o gestor administrativo, o técnico responsável pelo programa de uso público e com os guarda-parques, que atualmente realizam a condução de visitantes nas trilhas. Nestes encontros foram discutidas as demandas em relação às atividades de educação e interpretação ambiental no PNMO. Uma vez identificada a demanda objeto deste trabalho, foram realizadas visitas à trilha indicada pelos gestores, com o objetivo de obter informações prévias para posterior realização do inventário interpretativo. Foi realizado também um mapeamento da mesma com o auxílio de um sistema de posicionamento geográfico (GPS). Por fim, procedeu-se uma revisão bibliográfica e documental das informações referentes ao Parque, com destaque para o seu Plano de Manejo.

\section{Identificação do público-alvo}

O estabelecimento do público-alvo foi decorrente dos contatos realizados com os gestores do Parque, os quais informaram os usuários predominantes das trilhas agendadas, assim como 0 seu perfil. Um aprofundamento das características do público-alvo foi obtido em Silva (2015), que desenvolveu estudo sobre a percepção ambiental de alunos de $5^{\circ}$ a $8^{\circ}$ ano da rede pública estadual em relação a uma trilha do PNMO.

\section{Definição dos objetivos e do tema}

Os objetivos para a trilha foram definidos em função da demanda dos gestores, à luz daqueles estabelecidos no Plano de Manejo do Parque, em seu subprograma de Educação e Interpretação Ambiental. Para a definição do tema da trilha foram observados os objetivos propostos e o levantamento prévio realizado na trilha, buscando-se formular uma mensagem simples, direta e de fácil compreensão para o público-alvo.

\section{Realização do inventário interpretativo}

Em função dos objetivos, do público-alvo e do tempo necessário para a realização das atividades interpretativas na trilha, estabeleceu-se um número máximo de seis pontos interpretativos. Para a seleção desses pontos utilizou-se o método Indicadores de Atratividade de Pontos Interpretativos (IAPI), proposto por Magro e Freixêdas (1998), adaptado por Vasconcellos (2006). O método consistiu em quatro fases:

Fase 1 - Levantamento dos pontos potenciais para a interpretação: após a escolha do tema, e com base no levantamento prévio e mapeamento da trilha, foram selecionados 10 pontos potenciais para a interpretação do tema. Cada ponto pré-selecionado foi identificado com um nome. 
Fase 2 - Levantamento e seleção de indicadores: a seleção dos indicadores de atratividade foi feita com base no levantamento prévio da trilha $e$ em bibliografia correlata (RECH; CANTO-SILVA, 2012). O Quadro 1 apresenta os Indicadores de atratividade selecionados e as respectivas pontuações adotadas na avaliação dos pontos interpretativos.

Quadro 1 - Indicadores de atratividade e respectivas pontuações adotadas na seleção dos pontos interpretativos.

\begin{tabular}{|l|c|}
\hline \multicolumn{1}{|c|}{ Indicador de Atratividade } & Categorias (pontuação) \\
\hline Espaço disponível (em quantidade de pessoas) & 1 a 5 (1); 6 a 10 (2); 11 a 20 (3) \\
\hline Estímulo & Visual (1 a 2); Auditivo (1); Tátil (1); Olfativo (1) \\
\hline Percepção da Água & Visual (3); Sonora (2) \\
\hline Vegetação significativa (exótica ou ilustrativa) & Quantidade de espécies \\
\hline Presença ou sinais de animais (sons, vestígios, etc.) & (0 a 3) \\
\hline Beleza cênica & (0 a 3) \\
\hline Valor histórico cultural & (2) \\
\hline Presença de Epífitas & (2) \\
\hline Presença de Bioindicadores & Ausente (0); Pouco (1); Médio (2); Muito (3) \\
\hline Conforto &
\end{tabular}

Fase 3 - Elaboração e uso da Ficha de Campo: após a definição dos indicadores de atratividade e suas respectivas pontuações, foi elaborada uma ficha de campo para possibilitar a avaliação dos pontos interpretativos. A avaliação foi realizada em campo por uma dupla de pesquisadores. Ao longo do processo, estes atribuíram pontuações por consenso, conforme critérios estabelecidos no Quadro 1.

Fase 4 - Seleção Final: após a avaliação da atratividade de cada ponto interpretativo, com base nos indicadores, procedeu-se a soma das pontuações obtidas. Em seguida, os pontos interpretativos foram ordenados em ordem decrescente de pontuação final obtida, sendo selecionados os seis primeiros. Procedeu-se algumas adaptações no sentido de melhor utilizar os resultados alcançados.

\section{Análise das oportunidades interpretativas}

Após a definição dos pontos interpretativos a serem abordados, foi realizada uma análise das oportunidades interpretativas oferecidas por eles. Para tal, procedeu-se um levantamento expedito da composição da vegetação, 
da presença de avifauna e de outros aspectos ambientais significativos, sob o ponto de vista do tema selecionado para a trilha.

O levantamento da vegetação foi realizado com o auxílio de um pesquisador especialista em botânica, que procedeu a identificação das espécies ainda em campo. O levantamento da avifauna foi realizado com base no registro sonoro das suas vocalizações em cada ponto interpretativo por cinco minutos. Posteriormente, a identificação das vocalizações foi feita por comparação com os registros contidos em banco de dados de vocalizações das aves da Trilha de Educação Ambiental do PNMO (COSTA et al., 2016). Por fim, o levantamento de outros aspectos ambientais significativos foi feito com base na observação direta dos pesquisadores na trilha, sendo feita posteriormente uma categorização dos mesmos. Ao final, é apresentada uma síntese das oportunidades interpretativas associadas a cada ponto, sob a forma da definição de subtemas para estes.

\section{Seleção das estratégias interpretativas e proposição do roteiro}

Com base na análise das oportunidades interpretativas oferecidas em cada ponto selecionado, foram estabelecidas estratégias, constituídas por conteúdos informativos a serem abordados e atividades a serem conduzidas pelos intérpretes. Tais estratégias são apresentadas sob a forma de um roteiro, sendo utilizada a linguagem informal a ser empregada no momento da atividade interpretativa. Foram propostas duas atividades alternativas para cada ponto interpretativo, sendo algumas destas elaboradas a partir da adaptação de atividades ao ar livre propostas por Cornell (2008).

\section{Resultados e discussão}

\section{Identificação das oportunidades e necessidades do Parque}

A partir dos contatos realizados com os gestores do Parque foi identificada a existência de uma demanda, relativa ao desejo de reativar a trilha interpretativa de Baixo, anteriormente utilizada pelo Parque. Para tal, seria necessária a elaboração de um roteiro interpretativo.

A Trilha de Baixo (Figura 1) está situada na Zona de Uso Extensivo do Parque, constituída, em sua maior parte, por áreas naturais, podendo apresentar alguma alteração humana (SESTREN-BASTOS, 2006). O percurso da Trilha de Baixo tem início a partir de uma bifurcação da Trilha do Eixo Central, localizada em Zona de Uso Intensivo do Parque. A partir dessa bifurcação, a trilha percorre áreas de vassourais, matas em regeneração subxerofítica, matas altas higrófilas e campos de morros pedregosos. Ao longo da trilha também é possível depararse com um corpo d'água e vislumbrar antigas pedreiras. $O$ percurso total da trilha é de aproximadamente 600 metros, com ganho de elevação de apenas 14 metros, constituindo-se numa trilha de fácil execução. A trilha tem o seu fim caracterizado pelo reencontro com a Trilha do Eixo Central. 


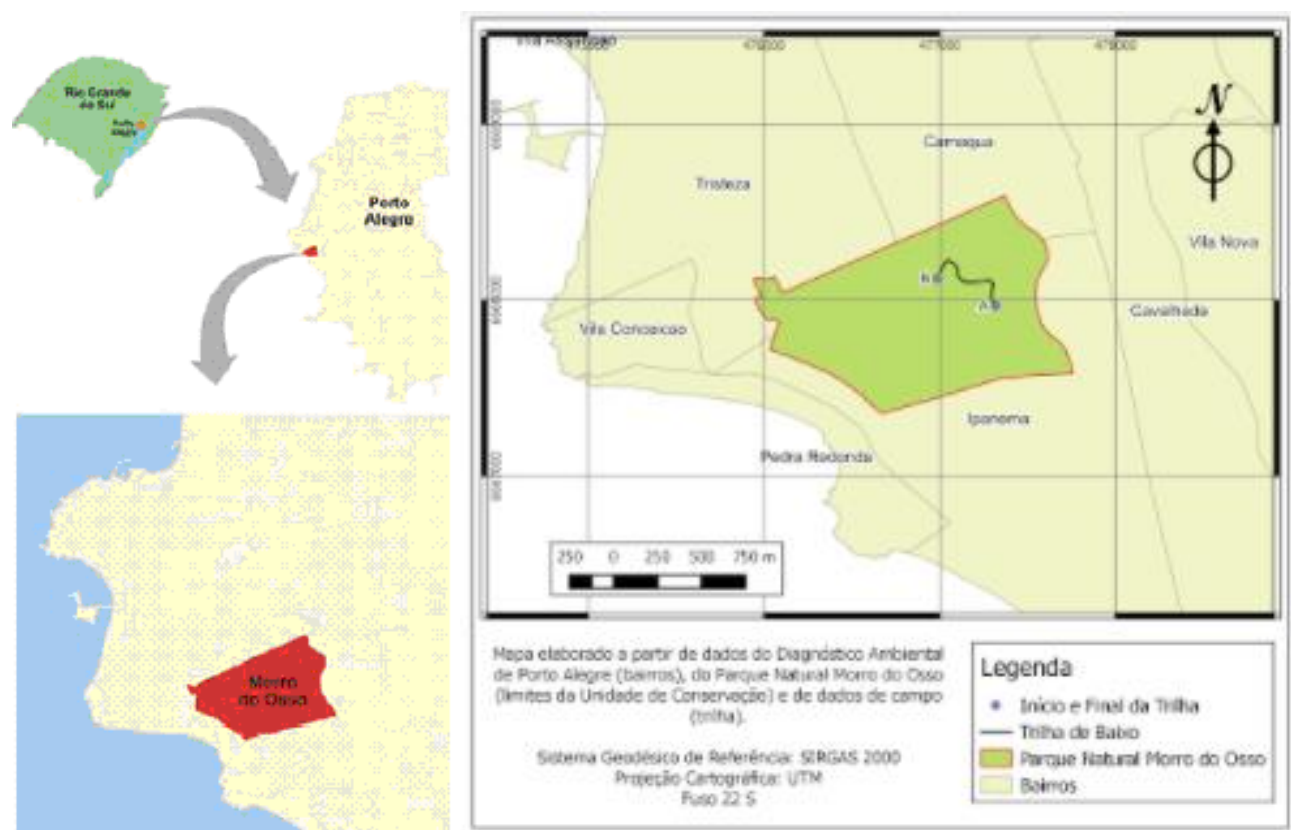

Figura 1: Mapas de localização da Trilha de Baixo e do Parque Natural Morro do Osso em escala local, no município de Porto Alegre (RS), e em escala regional.

Fonte: Autores (2017), adaptado de Sestren-Bastos (2006).

\section{Identificação do público-alvo}

De acordo com informações fornecidas pelos gestores do Parque, o público-alvo desejado para o programa interpretativo na Trilha de Baixo deveria ser constituído por alunos do ensino fundamental. Isto em face da facilidade de executar o trajeto e do menor esforço necessário para tal, quando comparado a outras trilhas do Parque.

Silva (2015), em trabalho de percepção ambiental realizado em outra trilha do PNMO com alunos de cinco turmas de $5^{\circ}$ a $8^{\circ}$ ano da rede pública estadual, constatou que o processo de percepção se desenvolveu em etapas, iniciando-se com o aparente desinteresse e falta de atenção, para em seguida passar para um processo de contemplação da paisagem e do ambiente. A partir desse momento, a curiosidade se aguçou em busca do conhecimento ou reconhecimento dos elementos que compõem o ambiente da trilha. Com base no uso de fotografias e nas categorias de percepção propostas por Bitt-Monteiro (2000), Silva (2015) evidenciou que a percepção dos alunos avaliados se enquadrou nas três categorias propostas: percepção da paisagem, percepção do extraordinário e percepção confraternizada. Assim, conclui-se que o ambiente do Parque pode ser percebido pelos escolares dessa faixa etária tanto a partir de sua paisagem, quanto dos fenômenos significativos do ambiente e das vivências compartilhadas. 


\section{Definição dos objetivos e do tema}

Com base na demanda dos gestores, no objetivo de promover a compreensão do ambiente do Parque visando a sua conservação, no conhecimento do público-alvo e das características da área, foi definido o seguinte tema: "O homem e os processos naturais transformam a paisagem".

\section{Realização do inventário interpretativo}

A partir da escolha do tema, e com base no levantamento prévio e mapeamento da trilha, foram selecionados os seguintes pontos interpretativos potenciais a serem submetidos à análise de sua atratividade: Vassoural, Corredor Verde, Mata de Transição, Fungos Orelha-de-Pau, Mata Higrófila, Curso d'Água, Matacão, Pedreira, Campo e Mata das Acácias-Velhas.

Após a avaliação da atratividade dos pontos interpretativos em potencial, realizada através de planilha de campo, foram obtidas as pontuações, conforme a Figura 2.

A partir dos resultados contidos na Figura 2, e considerando-se que os pontos Mata Higrófila e Curso D'água, que obtiveram a mesma pontuação, são muito próximos na trilha, selecionou-se os seguintes pontos para compor o roteiro interpretativo (Figura 3): Mata Higrófila, Campo, Corredor Verde, Pedreira, Mata das Acácias Velhas e Fungos Orelha-de-Pau.

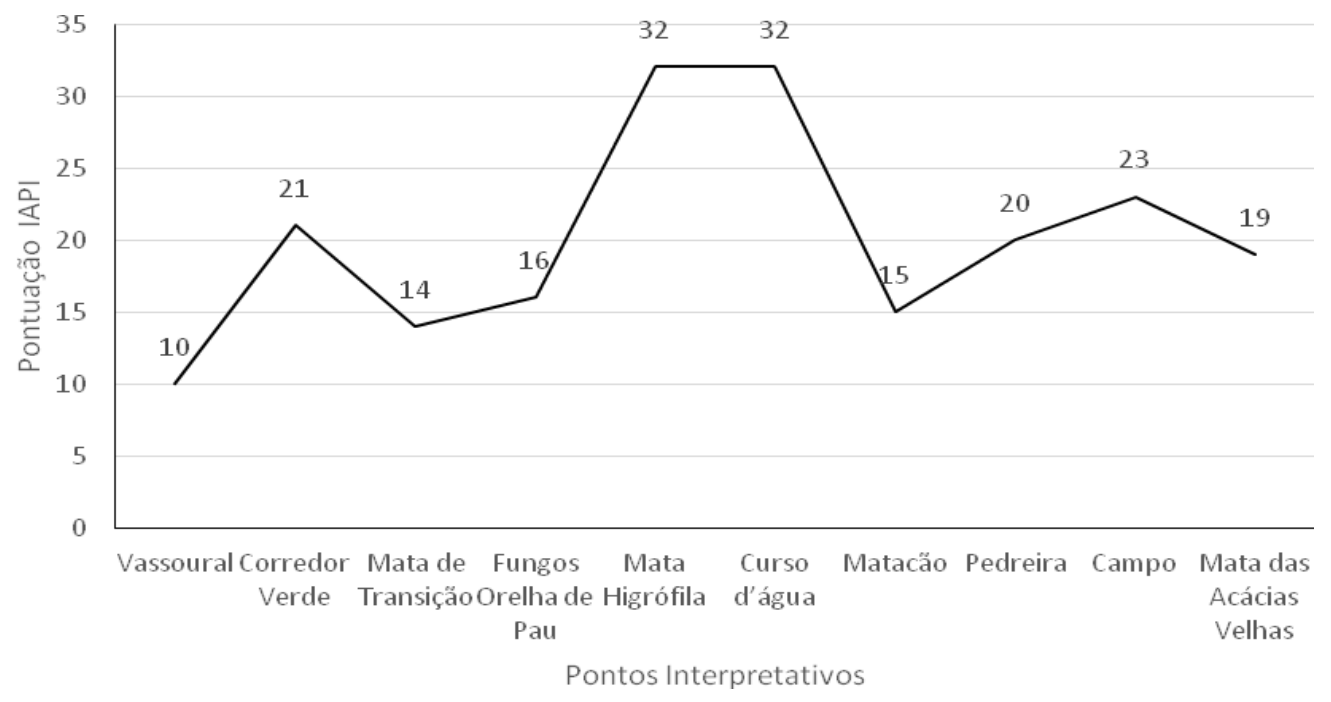

Figura 2: Pontuações finais da atratividade dos pontos interpretativos em potencial da Trilha de Baixo, do Parque Natural Morro do Osso, Porto Alegre, RS, pelo método IAPI.

Fonte: autores (2017). 


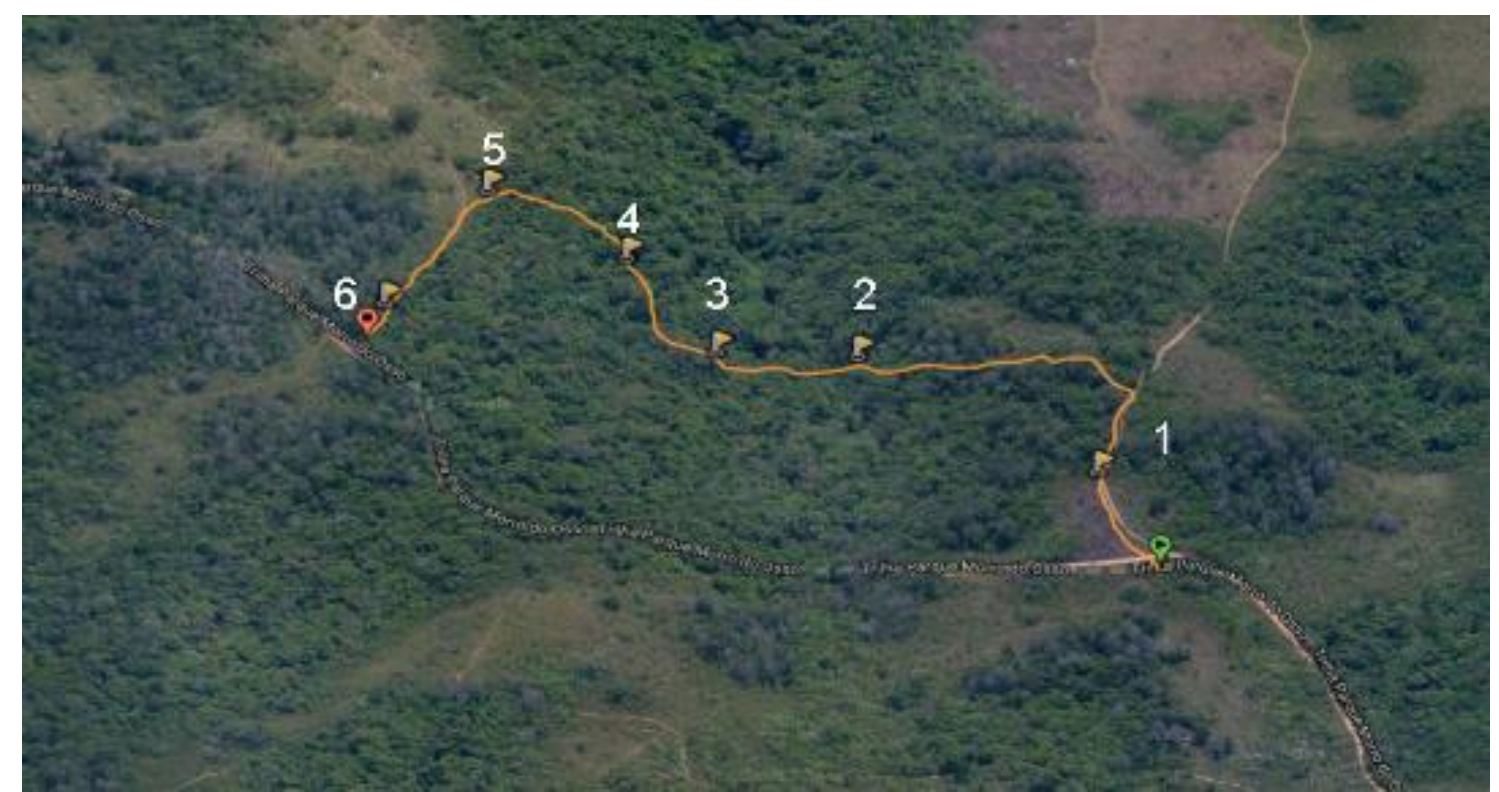

Figura 3: Identificação dos pontos interpretativos da Trilha de Baixo. 1: Corredor Verde; 2: Fungos Orelha-de Pau; 3: Mata Higrófila; 4: Pedreira; 5: Campo; 6: Mata das Acácias Velhas. Fonte: autores (2017).

\section{Análise das oportunidades interpretativas}

No que diz respeito à presença de avifauna nos pontos interpretativos (Tabela 1, próxima página), o levantamento registrou 13 espécies, sendo que o ponto Pedreira foi o que o registrou maior diversidade.

O levantamento da vegetação associada aos pontos interpretativos (Tabela 2, adiante) registrou um total de 31 espécies de árvores, sendo que o ponto Corredor Verde foi aquele que apresentou maior diversidade, com 14 espécies. Os pontos Mata Higrófila e Campo foram aqueles que apresentaram vegetação mais diferenciada em relação aos demais pontos, enquanto os pontos Corredor Verde, Fungos Orelha-de-pau e Mata das Acácias Velhas foram aqueles com manifestaram maior interferência humana, pela presença da Acácia Negra, espécie exótica. 
Tabela 1: Levantamento da avifauna associada aos pontos interpretativos da Trilha de Baixo, Parque Natural Morro do Osso, Porto Alegre, RS. 1: Corredor Verde; 2: Fungos Orelha-depau; 3: Mata Higrófila; 4: Pedreira; 5: Campo; 6: Mata das Acácias Velhas.

\begin{tabular}{|c|c|c|c|c|c|c|}
\hline \multirow[t]{2}{*}{ Nome científico (nome popular) } & \multicolumn{6}{|c|}{ Pontos Interpretativos } \\
\hline & 1 & 2 & 3 & 4 & 5 & 6 \\
\hline Coereba flaveola (Cambacica) & & $x$ & & $x$ & $x$ & \\
\hline Cyclarhis gujanensis (Pitiguari) & $x$ & $x$ & $x$ & $x$ & $x$ & $\mathrm{X}$ \\
\hline Furnarius rufus (João-de-barro) & & $x$ & $x$ & & $x$ & \\
\hline Leptotila rufaxilla (Juriti-gemedeira) & $\mathrm{X}$ & & & & & \\
\hline Leptotila verreauxi (Juriti-pupu) & & $x$ & $\mathrm{X}$ & $x$ & & $\mathrm{X}$ \\
\hline Myiopsitta monachus (Caturrita) & & & & $x$ & $x$ & \\
\hline Myiothlypis leucoblephara (Pula-pula Assobiador) & $x$ & & & $x$ & & $x$ \\
\hline Pitangus sulphuratus (Bem-te-vi) & $\mathrm{X}$ & $x$ & $\mathrm{X}$ & $x$ & $\mathrm{X}$ & $x$ \\
\hline Setophaga pitiayumi (Mariquita) & $\mathrm{X}$ & & & $x$ & & $x$ \\
\hline Thamnophilus caerulescens (Choca-da-mata) & & & & & & $x$ \\
\hline Turdus rufiventris (Sabiá-laranjeira) & $x$ & $x$ & $x$ & $x$ & $x$ & $x$ \\
\hline Vireo olivaceus (Juruviara) & & & $x$ & $x$ & & \\
\hline Zonotrichia capensis (Tico-tico) & $\mathrm{x}$ & $x$ & & & & \\
\hline
\end{tabular}

Fonte: autores (2017).

Tabela 2: Levantamento da vegetação associada aos pontos interpretativos da Trilha de Baixo, Parque Natural Morro do Osso, Porto Alegre, RS. 1: Corredor Verde; 2: Fungos Orelha-de-pau; 3: Mata Higrófila; 4: Pedreira; 5: Campo; 6: Mata das Acácias Velhas.

\section{Nome científico (nome popular)}

Acacia mearnsii De Wild. (Acácia-negra)

Actinostemon concolor Müll.Arg. (Laranjeira-domato)

Alchornea triplinervia (Spreng.) M. Arg.

(Tanheiro)

Allophylus edulis Radlk. ex Warm.(Chal-chal)

Asparagus officinalis L. (Aspargo)

Asteraceae sp1

Asteraceae sp2 (Margarida-grande)

Asteraceae sp3 (Margarida-pequena)

Baccharis dracunculifolia DC. (Vassoura-

branca)

Campomanesia xanthocarpa O.Berg (Gabiroba)

Ceiba speciosa (A.St.-Hil., A.Juss. \& Cambess.)

Ravenna (Paineira)

Cordia verbenacea DC. (Erva-baleeira).

Cupania vernalis Cambess. (Camboatá-

vermelho)

Dalbergia frutescens (Vell.) Britton (Rabo-de-

bugio)
Pontos Interpretativos

$\begin{array}{cccccc}1 & 2 & 3 & 4 & 5 & 6 \\ X & X & & & & X \\ & & X & X & & X \\ X & & X & X & & \\ & & & X & & \end{array}$

$x$

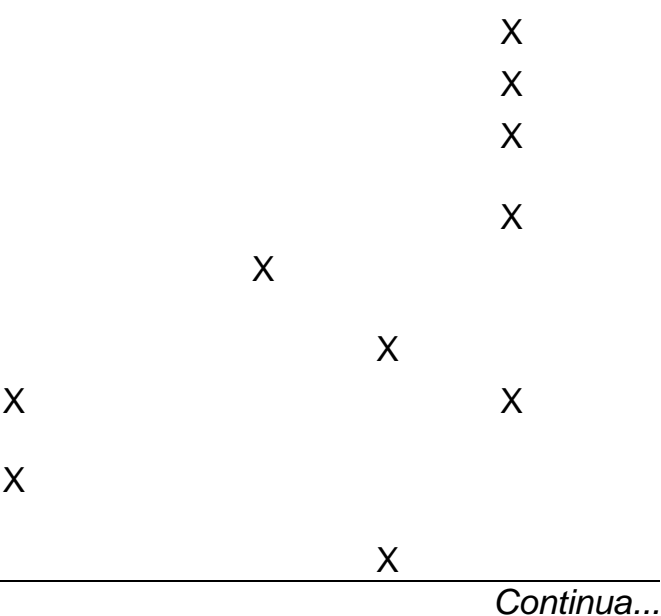


...continuação

\section{Nome científico (nome popular)}

Pontos Interpretativos

$\begin{array}{llllll}1 & 2 & 3 & 4 & 5 & 6\end{array}$

Dodonaea viscosa Sieber ex Schltdl.(Vassouravermelha)

$x$

Eryngium pristis Cham. \& Schltdl. (Gravatá mimoso)

Erythroxylum argentinum O.E.Schulz.(Cocãomiúdo)

Ficus L. (Figueira)

Hedyosmum brasiliense Miq. (Chá-de-bugre)

Lithraea brasiliensis Marchand. (Aroeira-brava)

Luehea divaricata Mart.(Açoita-cavalo)

Myracrodruon urundeuva M.Allemão (Aroeira grande)

Myrciaria cuspidata O.Berg (Camboim)

Myrsine coriacea (Sw.) R.Br. (Capororoca-dafolha-miúda),

Myrsine umbellata Mart. (Capororocão),

Schinus molle L.(Aroeira-piriquita)

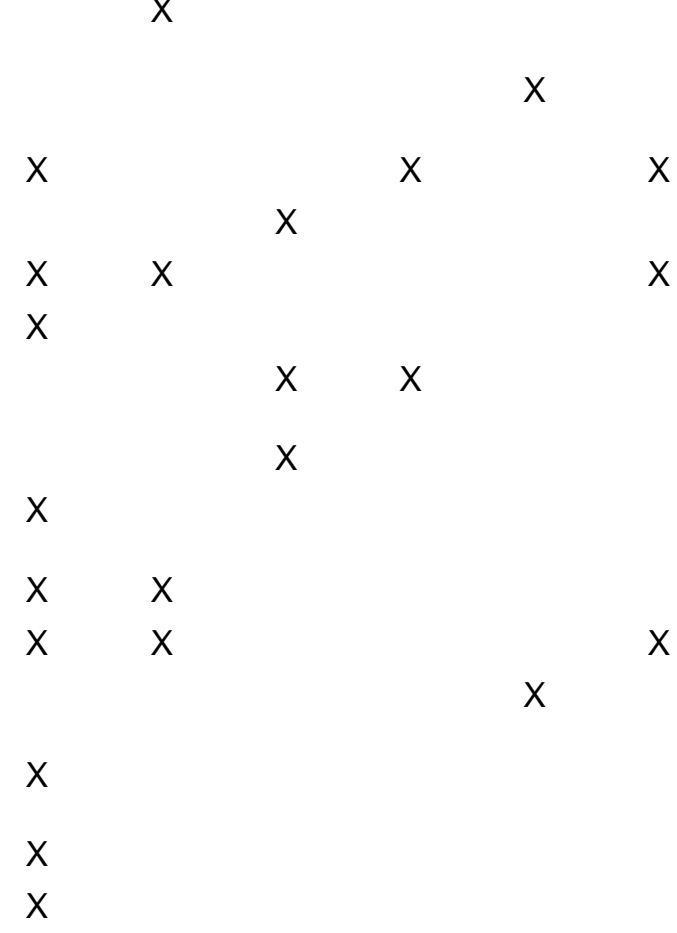

Schinus terebinthifolius Raddi (Aroeira vermelha )

Senecio brasiliensis Spreng. ex Baker. (Mariamole)

Solanum aculeatissimum Jacq. (Mata-cavalo)

Sorocea bonplandii (Baill.) W.C.Burger, Lanj. \&

Wess.Boer (Cincho)

$X$

Zanthoxylum rhoifolium Lam. (Mamica de cadela).

Fonte: autores (2017).

A Tabela 3 apresenta os resultados obtidos para o levantamento de outros aspectos significativos do ambiente nos pontos interpretativos. No ponto Corredor Verde é evidente a ocorrência de aspectos relacionados à diversidade das interações ecológicas. No ponto Fungos Orelha-de-pau, chama a atenção a diversidade de fungos. No ponto Mata Higrófila, registrou-se a quase totalidade das categorias elencadas, evidenciando um ambiente mais rico e complexo. No ponto Pedreira, evidencia-se principalmente a presença de vestígios de atividades humanas e árvores de grande porte. Já no ponto Campo, novamente, é evidenciado um ambiente rico em evidências de animais, principalmente de insetos. Por fim, no ponto Mata das Acácias Velhas há evidências de um ambiente em transformação devido aos processos de decomposição orgânica. 
Tabela 3 - Levantamento de aspectos significativos do ambiente associados aos pontos interpretativos da Trilha de Baixo, Parque Natural Morro do Osso, Porto Alegre, RS. 1: Corredor Verde; 2: Fungos Orelha-de-pau; 3: Mata Higrófila; 4: Pedreira; 5: Campo; 6: Mata das Acácias Velhas.

\begin{tabular}{|c|c|c|c|c|c|c|}
\hline \multirow[t]{2}{*}{ Aspectos signficativos } & \multicolumn{6}{|c|}{ Pontos Interpretativos } \\
\hline & 1 & 2 & 3 & 4 & 5 & 6 \\
\hline Abrigos e estruturas produzidas por animais & $\mathrm{X}$ & & $\mathrm{x}$ & & $\mathrm{X}$ & \\
\hline Interações ecológicas & $x$ & $x$ & & & & \\
\hline Diversidade de cores e formas & $x$ & & $x$ & & $\mathrm{X}$ & $\mathrm{X}$ \\
\hline Diversidade de insetos & $x$ & $x$ & $\mathrm{x}$ & & & \\
\hline Diversidade de fungos, líquens e musgos & & $X$ & $\mathrm{X}$ & $\mathrm{X}$ & & \\
\hline Bioindicadores & & $x$ & & & & \\
\hline Rochas de grandes proporções & & & $x$ & & & \\
\hline Presença de água & & & $\mathrm{X}$ & & $\mathrm{X}$ & \\
\hline Decomposição foliar & & & $x$ & & & $x$ \\
\hline Vestígios humanos & & & & $x$ & & \\
\hline Árvores de grandes proporções & & & $x$ & $x$ & & \\
\hline
\end{tabular}

Fonte: autores (2017).

Com base nos três levantamentos realizados, foi possível identificar várias oportunidades interpretativas relacionadas aos pontos, sendo sugeridos os seguintes subtemas:

- Ponto Corredor Verde - interações ecológicas;

- Ponto Fungos Orelha-de-Pau - decomposição vegetal;

- Ponto Mata Higrófila - percepção do extraordinário;

- Ponto Pedreira - homem na natureza;

- Ponto Campo - paisagem diferente;

- Ponto Mata das Acácias Velhas - ciclo da vida.

\section{Seleção das estratégias interpretativas e proposição do roteiro}

Com base nos subtemas sugeridos e no contexto do tema da trilha como um todo, o Quadro 2 apresenta uma proposta de roteiro interpretativo, contendo textos e atividades que podem ser desenvolvidas em cada ponto interpretativo. 
Quadro 2: Proposta de roteiro interpretativo para a Trilha de Baixo, Parque Natural Morro do Osso, Porto Alegre (RS).

\begin{tabular}{|c|c|c|c|}
\hline Ponto Interpretativo & Fala do Intérprete & Atividade 1 & Atividade 2 \\
\hline Corredor Verde & $\begin{array}{l}\text { Este ponto registra o início da nossa } \\
\text { aventura pela Trilha de Baixo. Nosso } \\
\text { caminho é de pouco mais de } 600 \text { metros e } \\
\text { nele compartilharemos muitas emoções, } \\
\text { informações, atividades e desafios. Ao } \\
\text { longo da trilha buscaremos entender um } \\
\text { pouco sobre a forma como a natureza e o } \\
\text { homem juntos constroem a paisagem, ou } \\
\text { seja, constroem as características } \\
\text { perceptíveis do ambiente. Neste ponto da } \\
\text { trilha começaremos a perceber a } \\
\text { complexidade das interações no ambiente. } \\
\text { Mas para isso, primeiro é necessário } \\
\text { aguçarmos nossos sentidos, pois na cidade } \\
\text { nem sempre utilizamos muito bem todos } \\
\text { eles. Para isso vou propor uma brincadeira } \\
\text { (realizar a atividade 1). Após nossa } \\
\text { brincadeira vamos conversar um pouco } \\
\text { sobre algumas interações entre os } \\
\text { organismos no ambiente. (A atividade } 2 \text { é } \\
\text { opcional) }\end{array}$ & $\begin{array}{l}\text { Sons do ambiente } \\
\text { Subtema: interações ecológicas } \\
\text { Objetivos: concentrar a atenção; desenvolver a } \\
\text { percepção auditiva; destacar a diversidade do } \\
\text { ambiente. } \\
\text { Materiais necessários: nenhum. } \\
\text { Descrição: as crianças sentam-se em círculo com } \\
\text { os olhos fechados e as mãos levantadas. Cada vez } \\
\text { que alguém ouvir um canto de pássaro novo, } \\
\text { levantará um dedo. Ao final é feita uma contagem } \\
\text { para ver quem ouviu mais cantos diferentes. Após } \\
\text { a brincadeira, pode-se também pedir que, ainda de } \\
\text { olhos fechados, as crianças busquem ouvir outros } \\
\text { sons do ambiente, como o vento, barulho de } \\
\text { insetos, o movimento dos animais, de folhas ou } \\
\text { ainda sons da cidade. }\end{array}$ & $\begin{array}{l}\text { Predador/presa } \\
\text { Subtema: interações ecológicas } \\
\text { Objetivos: entusiasmar os participantes; ilustrar as } \\
\text { relações ecológicas que ocorrem no ambiente; } \\
\text { compreender a importância de cada ser vivo na cadeia } \\
\text { alimentar. } \\
\text { Materiais necessários: vendas. } \\
\text { Descrição: as crianças devem formar um círculo e dar } \\
\text { as mãos. Duas crianças serão vendadas, sendo que } \\
\text { uma será a presa e a outra o predador. Essas duas } \\
\text { crianças irão para o meio do círculo. O predador } \\
\text { tentará capturar a presa, ouvindo os sons e sentindo } \\
\text { seus movimentos. O silêncio deve ser absoluto. Se o } \\
\text { predador ou presa chegar muito perto das crianças do } \\
\text { círculo, elas devem dar pequenas cutucadas neles } \\
\text { para que percebam que devem ir mais para o círculo. }\end{array}$ \\
\hline $\begin{array}{c}\text { Fungos Orelha-de- } \\
\text { pau }\end{array}$ & $\begin{array}{l}\text { Neste ponto, vamos começar fazendo uma } \\
\text { brincadeira (realizar a atividade 1). Agora } \\
\text { que vocês descobriram os fungos orelhas- } \\
\text { de-pau, peço que observem as árvores em } \\
\text { que eles estão grudados. Elas estão vivas } \\
\text { ou mortas? Sim, elas estão mortas. Estes } \\
\text { fungos são decompositores e sempre estão } \\
\text { associados a árvores que se encontram } \\
\text { mortas. Na verdade, eles estão se } \\
\text { alimentando dos tecidos mortos dessas } \\
\text { plantas, ajudando a decompô-los. Assim, da } \\
\text { mesma forma que os cupins, os fungos } \\
\text { decompositores têm um papel importante na } \\
\text { natureza, ajudando a reaproveitar os } \\
\text { nutrientes dos organismos que morrem. (A } \\
\text { atividade } 2 \text { é opcional) }\end{array}$ & $\begin{array}{l}\text { Imagem ampliada } \\
\text { Subtema: decomposição vegetal } \\
\text { Objetivos: chamar a atenção para os fungos do } \\
\text { local; destacar a importância dos fungos no } \\
\text { processo de ciclagem de nutrientes, através da } \\
\text { decomposição; mostrar a diversidade biológica da } \\
\text { trilha. } \\
\text { Materiais necessários: imagens ampliadas de } \\
\text { fungos da trilha. } \\
\text { Descrição: o intérprete apresentará às crianças } \\
\text { uma ou mais imagens ampliadas de fungos } \\
\text { orelhas-de-pau. Os alunos deverão observar a } \\
\text { imagem e tentar descobrir qual elemento do } \\
\text { espaço corresponde àquela imagem. Após a } \\
\text { atividade, o intérprete deverá continuar a sua fala. }\end{array}$ & $\begin{array}{l}\text { Morto/vivo } \\
\text { Subtema: decomposição vegetal } \\
\text { Objetivos: despertar o interesse; destacar a } \\
\text { importância dos fungos no processo de ciclagem de } \\
\text { nutrientes, através da decomposição. } \\
\text { Materiais necessários: nenhum. } \\
\text { Descrição: O intérprete dirá "morto" ou "vivo" e as } \\
\text { crianças deverão seguir a posição indicada. Na } \\
\text { posição "morto" devem ficar agachadas, na posição } \\
\text { "vivo" devem ficar em pé. Quem errar sai da } \\
\text { brincadeira. }\end{array}$ \\
\hline
\end{tabular}

Revbea, São Paulo, V. 13, № 3: 122-142, 2018. 


\begin{tabular}{|c|c|c|c|}
\hline Mata Higrófila & $\begin{array}{l}\text { Neste ponto da trilha é possível } \\
\text { percebermos a diferença da temperatura em } \\
\text { relação à parte inicial dela. O local é muito } \\
\text { mais fresco e úmido. O que torna o } \\
\text { ambiente assim são as plantas, que retiram } \\
\text { a água do solo e a transferem para o ar, } \\
\text { através da sua transpiração. Neste local, } \\
\text { como vemos, há bastante água. Assim, as } \\
\text { árvores crescem mais e estão em maior } \\
\text { quantidade, fazendo com que haja uma } \\
\text { grande quantidade de outros organismos } \\
\text { também. Percebe-se, portanto, a a } \\
\text { importância de se conservar a vegetação } \\
\text { nas cidades. Agora vamos explorar essa } \\
\text { diversidade. (Realizar uma das atividades) }\end{array}$ & $\begin{array}{l}\text { Registrando o ambiente } \\
\text { Subtema: percepção do extraordinário } \\
\text { Objetivos: despertar o interesse; estabelecer um } \\
\text { vínculo afetivo, através de uma lembrança que } \\
\text { pode ser guardada; sensibilizar quanto a } \\
\text { diversidade de cada elemento do ambiente. } \\
\text { Materiais necessários: folhas de ofício e giz de } \\
\text { cera. } \\
\text { Descrição: os participantes receberão uma folha e } \\
\text { um giz de cera. Deverão escolher algo do ambiente } \\
\text { para registrar. Pode ser uma folha caída, o tronco } \\
\text { de uma árvore, uma pedra, uma pegada, etc. Após } \\
\text { escolher, deverão colocar a folha sobre o elemento } \\
\text { escolhido e passar o giz de cera deitado sobre ela. } \\
\text { Assim, uma "xerox" do elemento será registrada. } \\
\text { Depois de todos registrarem, cada um comentará } \\
\text { sobre o que registrou. }\end{array}$ & $\begin{array}{l}\text { Máquina fotográfica humana } \\
\text { Subtema: percepção do extraordinário } \\
\text { Objetivos: despertar o interesse; estabelecer vínculos } \\
\text { afetivos com o local; sensibilizar quanto a diversidade } \\
\text { de cada elemento no ambiente; contemplar a beleza } \\
\text { do ambiente. } \\
\text { Materiais necessários: nenhum } \\
\text { Descrição: O grupo de alunos será dividido em } \\
\text { duplas. Um dos alunos será o fotógrafo e o outro a } \\
\text { máquina fotográfica. O participante que for escolhido } \\
\text { como máquina fotográfica, deve manter os olhos } \\
\text { fechados. O fotógrafo o guiará pelo espaço até } \\
\text { encontrar o cenário que deseja fotografar. Ao } \\
\text { encontrar o cenário e posicionar a máquina fotográfica, } \\
\text { precisará dar um sinal ao colega de olhos fechados } \\
\text { para que os abra. O sinal pode ser o que o aluno } \\
\text { quiser, pode "apertar um botão" ou falar "click", por } \\
\text { exemplo. O participante que for a máquina fotográfica } \\
\text { abrirá os olhos e fechará, rapidamente, como a lente } \\
\text { de uma câmera. É só uma piscada. Agora se invertem } \\
\text { as posições. Ao final, cada um comenta sobre o que } \\
\text { registrou. }\end{array}$ \\
\hline Pedreira & $\begin{array}{l}\text { Vamos fazer mais uma brincadeira (realizar } \\
\text { a atividade 1). O Morro do Osso é formado } \\
\text { por rochas muito antigas, chamadas de } \\
\text { granito. Essas rochas vão se } \\
\text { desmanchando com o tempo, naturalmente, } \\
\text { formando o solo do morro. Entretanto, elas } \\
\text { também podem ser extraídas e utilizadas } \\
\text { pelo homem em suas construções. Por isso, } \\
\text { no passado, antes do morro virar um } \\
\text { parque, existiam várias pedreiras de onde } \\
\text { eram retirados blocos de pedra que } \\
\text { ajudaram a erguer construções na cidade. } \\
\text { As rochas com faces parelhas e retilíneas, } \\
\text { apresentando pequenos orifícios ou } \\
\text { ranhuras, são evidências desse tempo. Elas } \\
\text { ajudam, assim, a contar a história da } \\
\text { relação da cidade com o Morro. (A atividade } \\
2 \text { é opcional) }\end{array}$ & $\begin{array}{l}\text { A Brincadeira do nariz } \\
\text { Subtema: homem na natureza } \\
\text { Objetivos: concentrar a atenção; desenvolver o } \\
\text { raciocínio lógico; desenvolver a criatividade; } \\
\text { compreender a importância de cada ser vivo. } \\
\text { Materiais necessários: cartas com pistas. } \\
\text { Descrição: a brincadeira é um jogo de pistas. O } \\
\text { intérprete dará pistas para a identificação dos } \\
\text { blocos de granito de uma antiga pedreira. Uma } \\
\text { pista será lida de cada vez. Se o participante achar } \\
\text { que sabe a que se refere, deve segurar o nariz. } \\
\text { Não pode falar. Então, o intérprete lerá a próxima } \\
\text { pista. Se o participante ainda achar que sabe, deve } \\
\text { manter o dedo no nariz. Mas, se ele perceber que } \\
\text { estava errado, deve tirar o dedo do nariz. E assim a } \\
\text { brincadeira continua até que todos estejam } \\
\text { segurando o nariz. }\end{array}$ & $\begin{array}{l}\text { Até onde ela vai? } \\
\text { Subtema: homem na natureza } \\
\text { Objetivos: despertar a atenção; compreender as } \\
\text { diversas formas de dispersão das sementes; } \\
\text { compreender a importância das sementes no ciclo de } \\
\text { vida da floresta. } \\
\text { Materiais necessários: nenhum } \\
\text { Descrição: Em determinado período do ano, a única } \\
\text { paineira presente na área começa a liberar suas } \\
\text { sementes envoltas por um tipo de algodão, a paina! } \\
\text { Elas voam pela trilha. Até onde será que vão? A } \\
\text { atividade é essa! Até quantos passos de distância da } \\
\text { árvore encontramos sementes da paineira? Ao final } \\
\text { deve ser contada a estória dos travesseiros que são } \\
\text { feitos com as painas das paineiras. }\end{array}$ \\
\hline
\end{tabular}

Revbea, São Paulo, V. 13, № 3: 122-142, 2018. 


\begin{tabular}{|c|c|c|c|}
\hline Campo & $\begin{array}{l}\text { Neste ponto é oportuno chamar a atenção } \\
\text { sobre o campo e a importância da sua } \\
\text { preservação. Aqui no parque, a mata vem } \\
\text { tomando o lugar do campo e, com isso, } \\
\text { ameaça à sobrevivência da vegetação } \\
\text { herbácea e dos vários animais que } \\
\text { dependem dela para viver, como preás, } \\
\text { lagartos, cobras, algumas aves e diversos } \\
\text { insetos. Embora isso ocorra de forma } \\
\text { natural, não se deve apressar esse } \\
\text { processo com interferências causadas pelo } \\
\text { homem. É importante lembrar também que } \\
\text { os campos são as paisagens típicas do Rio } \\
\text { Grande do Sul, sendo aqui chamados de } \\
\text { Pampa. Além disso, eles desempenham } \\
\text { importante papel no ciclo da água, } \\
\text { diminuindo o escoamento das águas da } \\
\text { chuva e promovendo a sua infiltração no } \\
\text { solo. Vamos investigar? (Realizar uma das } \\
\text { atividades) }\end{array}$ & $\begin{array}{l}\text { Procurando animais } \\
\text { Subtema: paisagem diferente } \\
\text { Objetivos: despertar o espírito investigativo; } \\
\text { desenvolver estratégias em equipe; criar um } \\
\text { vínculo afetivo com o espaço, através de uma } \\
\text { aventura. } \\
\text { Materiais necessários: folhas de ofício e caneta. } \\
\text { Descrição: os participantes serão divididos em } \\
\text { duplas ou trios. Cada um deve pegar uma folha de } \\
\text { ofício e uma caneta. A tarefa é simples: procurar } \\
\text { animais ou evidências de que eles passaram por } \\
\text { ali. É bom lembrá-los que insetos e aranhas } \\
\text { também são animais. Eles precisam anotar cada } \\
\text { evidência que achem. Eles têm } 2 \text { minutos para } \\
\text { procurar. Não devem correr. É preciso respeitar o } \\
\text { espaço e cuidar dele. }\end{array}$ & $\begin{array}{l}\text { Cadê? } \\
\text { Subtema: paisagem diferente } \\
\text { Objetivos: desenvolver a concentração; despertar o } \\
\text { espírito investigativo; desenvolver estratégias em } \\
\text { equipe; criar um vínculo afetivo com o espaço, através } \\
\text { de uma aventura. } \\
\text { Materiais necessários: fotos do local. } \\
\text { Descrição: O intérprete apresentará algumas imagens } \\
\text { ao grupo. As imagens conterão fotos de elementos do } \\
\text { ambiente presentes naquele ponto da trilha, alguns } \\
\text { mais fáceis de achar, outros menos. Os participantes } \\
\text { devem procurar estes elementos no espaço, no menor } \\
\text { tempo possível. O grupo pode ser dividido em equipes. } \\
\text { O intérprete deve cronometrar o tempo gasto. O tempo } \\
\text { pode ser anotado em uma planilha. Assim, teremos } \\
\text { um ranking de todos os visitantes da trilha, e de quais } \\
\text { foram mais rápidos na procura. }\end{array}$ \\
\hline $\begin{array}{c}\text { Mata das Acácias } \\
\text { Velhas }\end{array}$ & $\begin{array}{l}\text { Esta árvore de tronco escuro é conhecida } \\
\text { como acácia-negra e é uma planta exótica, } \\
\text { ou seja, que não se originou na região, } \\
\text { sendo aqui introduzida pelo homem. } \\
\text { Percebemos neste ponto da trilha que } \\
\text { várias delas estão caídas. Isto aconteceu } \\
\text { porque já são bem velhas e fracas, sendo } \\
\text { derrubadas pelo vento. No seu lugar, outras } \\
\text { espécies estão nascendo - é a vida em } \\
\text { renovação. Bom, estamos chegando ao final } \\
\text { da nossa aventura. Nela percebemos a } \\
\text { importância do homem e da natureza na } \\
\text { transformação do ambiente. Mas antes de } \\
\text { sairmos da trilha, gostaria que vocês me } \\
\text { contassem se gostaram ou não da aventura. } \\
\text { (Realizar uma das atividades) }\end{array}$ & $\begin{array}{l}\text { Hora da verdade } \\
\text { Subtema: ciclo da vida } \\
\text { Objetivos: concentrar a atenção; refletir acerca da } \\
\text { trilha e do ambiente; desenvolver o vínculo afetivo } \\
\text { com o local. } \\
\text { Materiais necessários: nenhum } \\
\text { Descrição: o grupo fará um círculo ou um } \\
\text { retângulo. O intérprete pedirá que cada participante } \\
\text { diga o que mais gostou e o que menos gostou na } \\
\text { trilha. }\end{array}$ & $\begin{array}{l}\text { Compartilhando a aventura } \\
\text { Subtema: ciclo da vida } \\
\text { Objetivos: concentrar a atenção; refletir acerca da } \\
\text { trilha e do ambiente; desenvolver o vínculo afetivo com } \\
\text { o local. } \\
\text { Materiais necessários: nenhum } \\
\text { Descrição: o grupo fará um círculo ou um retângulo. } \\
\text { O intéprete convidará os participantes a contarem } \\
\text { uma história com ele. O intérprete começará com a } \\
\text { frase "Nesta trilha me diverti muito e aprendi que...". }\end{array}$ \\
\hline
\end{tabular}

Fonte: autores (2017) 


\section{Considerações finais}

O presente trabalho, assim como outros relacionados à elaboração de trilhas interpretativas, buscou prover os gestores de uma área protegida com um suporte para as atividades de interpretação ambiental, assim como oferecer metodologias que possam ser utilizadas na elaboração de outros roteiros interpretativos. Neste sentido, os objetivos traçados neste trabalho foram alcançados, uma vez que o roteiro interpretativo proposto pode ser efetivamente adotado pelos gestores do PNMO, caso seja julgado pertinente. De outra forma, a proposta vem acompanhada de uma descrição clara da metodologia empregada, a qual se constituiu de uma adaptação de outras metodologias já utilizadas, trazendo com isso uma contribuição inovadora para o tema.

A metodologia empregada na elaboração do roteiro interpretativo mostrou-se consistente, uma vez que considerou aspectos relevantes apontados por Vasconcellos (1998), referentes a identificação das oportunidades e necessidades da área, assim como do público-alvo, somados a uma grande ênfase dada para a análise das oportunidades interpretativas, conforme propõe Sharpe (1982, apud NASCIMENTO, 2004).

Assim, o conhecimento prévio da trilha e do público alvo a ser abordado no programa interpretativo foi de fundamental importância para a definição dos objetivos e do tema a ser abordado, assim como para a realização do inventário interpretativo. A proposição do tema "O homem e os processos naturais transformam a paisagem" retratou tanto os objetivos propostos no subprograma de Educação e interpretação ambiental do Parque, relacionados à promoção da compreensão do ambiente natural e das inter-relações da unidade, quanto buscou atender também uma das maneiras pelas quais 0 ambiente pode ser percebido pelos escolares da faixa etária abordada - a partir da sua paisagem. De outra forma, o método IAPI mostrou-se muito adequado para selecionar os principais pontos interpretativos elencados a partir do levantamento prévio da trilha.

Um dos aspectos principais a ser ressaltado neste trabalho foi a análise das oportunidades interpretativas, realizada em cada ponto selecionado. $O$ estudo expedito da vegetação, da avifauna e de outros aspectos significativos do ambiente possibilitou um maior conhecimento dos pontos interpretativos e, a partir disso, a avaliação de como poderiam contribuir para a construção do tema ao longo da trilha. A proposição de subtemas foi muito conveniente uma vez que o perfil de percepção do público-alvo apontou que o ambiente do Parque pode também ser percebido através dos seus fenômenos significativos. Atualmente, existe uma carência de trabalhos relacionados à elaboração de programas de interpretação em trilhas que se detenham em avaliar as oportunidades interpretativas oferecidas pelos pontos interpretativos, sendo em geral avaliadas as oportunidades relacionadas à trilha como um todo ou a um aspecto ambiental específico (CARVALHO; BÓÇON, 2004; MARTINS et al., 2007; IKEMOTO et al., 2009; BARCELOS et al., 2013; KRUG et al., 2015; 
CORRÊA; FIGUEIRÓ, 2017).

A proposição de uma estratégia interpretativa constituído por atividades lúdicas a serem desenvolvidas com o público alvo visou atender ao que sugere Beck e Cable (1998), no que diz respeito a adotar uma abordagem e um método fundamentalmente diferente, quando a interpretação for dirigida a crianças. As atividades propostas buscam, de forma lúdica, interpretar a paisagem e os fenômenos significativos do Parque, considerando o tema adotado para a trilha. Outro aspecto importante a ser ressaltado é o fato das atividades serem desenvolvidas de modo a possibilitar que as vivências sejam compartilhadas.

Por fim, fica evidente que o planejamento, seja mais sucinto ou mais elaborado, é uma etapa muito importante para a implantação de um programa interpretativo em trilhas. Certamente, um planejamento mais consistente, considerando diferentes aspectos em sua elaboração, facilita o alcance de programas interpretativos mais realistas e que estejam de acordo com as expectativas do público-alvo e dos gestores das áreas protegidas, cumprindo assim, de fato, com a função de contribuir para a Educação Ambiental realizada em UCs.

\section{Referências}

BARCELLOS, M.C.; MAIA, S.; MEIRELES, C; PIMENTEL, D.S. Elaboração da trilha interpretativa no Morro das Andorinhas: uma proposta de Educação Ambiental no Parque Estadual da Serra da Tiririca, RJ. Anais - Uso Público em Unidades de Conservação, n. 1, v. 1, 2013.

BECK, L.; CABLE, T. T. Interpretation for the 21st Century: Fifteen Guiding Principles for Interpreting Nature and Culture. USA: Sagamore Publi., 1998. 242p.

BITT-MONTEIRO, M. Teoria dos Universos Circundantes - Percepção, Espaço e Fotografia: uma abordagem metodológica. Revista de Biblioteconomia e Comunicação da UFRGS, v.8, 2000.

BRASIL. Decreto no 5.758, de 13 de abril de 2006. Institui o Plano Estratégico Nacional de Áreas Protegidas - PNAP, seus princípios, diretrizes, objetivos e estratégias, e dá outras providências. Diário Oficial da República Federativa do Brasil. Brasília, DF, 17 abr. 2006. Disponível em: http://www.planalto.gov.br/ccivil 03/ ato2004-2006/2006/decreto/d5758.htm.

Acesso em 20 de junho de 2017.

BRASIL. Lei no 9.795, de 27 de abril de 1999. Dispõe sobre a Educação Ambiental, institui a Política Nacional de Educação Ambiental e dá outras providências. Diário Oficial da República Federativa do Brasil. Brasília, DF, 28 abr. 1999. Disponível em: http://www.planalto.gov.br/ccivil 03/leis/19795.htm. Acesso em: 14 de julho de 2017. 


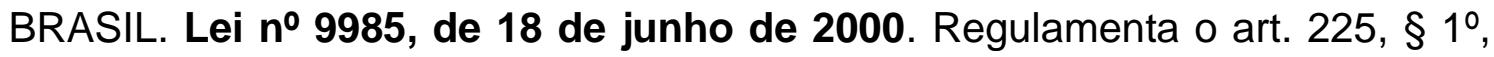
incisos I, II, III, e VII da Constituição Federal, institui o Sistema Nacional de Unidades de Conservação da Natureza e dá outras providências. Diário Oficial da República Federativa do Brasil. Brasília, DF, 19 jul. 2000. Disponível em: http://www.planalto.gov.br/ccivil 03/leis/19985.htm. Acesso em: 13 de junho de 2017.

BENSUSAN, N. Conservação da Biodiversidade em Áreas Protegidas. Rio de Janeiro: Editora FGV, 2006. 176 p.

CARVALHO, J; BÓÇON, R. Planejamento do traçado de uma trilha interpretativa através da caracterização florística. Revista Floresta, 34 (1), Jan/Abr 2004, 23-32, Curitiba-PR.

CHAGAS, R.R.D. O potencial dos espaços públicos de Aracaju (SE) como locais de desenvolvimento de práticas em Ecologia: sugestões e aplicação. 43p., 2005. Monografia de Conclusão de Curso. Departamento de Biologia, Universidade Federal de Sergipe, Aracaju, 2005.

CORNELL, J. Vivências com a Natureza. 3ª ed, São Paulo: Aquariana, 2008.

CORRÊA, L.R.; FIGUEIRÓ, A.S. Proposta de uma trilha interpretativa na Reserva Particular do Patrimônio Natural Estadual Mo'ã, Itaára (RS). Revista Brasileira de Ecoturismo, São Paulo, v.10, n.3, ago/out 2017, pp.628-644.

COSTA, A.M.; NASCIMENTO, C.A.; ACCORDI, I.; CANTO-SILVA, C.R. Levantamento da avifauna associada à trilha de Educação Ambiental do Parque Natural Morro do Osso, Porto Alegre, RS. Anais do $5^{\circ} \mathrm{SICT}$, Seminário de Iniciação Científica e Tecnológica do IFRS. 16 a 18 de novembro de 2016, Bento Gonçalves, RS.

GANEM, R.S (org.). Conservação da Biodiversidade: Legislação e Políticas Públicas. Brasília: Câmara dos Deputados, 2010. 434 p.

HIRATA, C.; PASCHOAL, J.D.; SOUZA, M.V.F. Observação, Vivência e Sensibilização nas Unidades de Conservação em Ambientes Urbanos. Revista Eletrônica Pro-Docência/UEL. Edição №. 5, Vol. 1, jul-dez. 2013.

IKEMOTO, S.M.; MORAES, M.G.; COSTA, V.C. Avaliação do potencial interpretativo da trilha do Jequitibá, Parque Estadual dos Três Picos, Rio de Janeiro. Soc. nat. (Online), Uberlândia, v. 21, n. 3, p. 271-287, 2009.

KRUG, A.L.; PEZENTI, M.; FRÓES, E.H.; MILANO, M.Z. Planejamento e implantação de uma trilha interpretativa na Mata Atlântica para atividades de Educação Ambiental no Instituto Federal Catarinense, Campus Rio do Sul. Anais da Mostra Nacional de Iniciação Científica e Tecnológica Interdisciplinar, 11212 de novembro de 2015.

MAGRO, T.C.; FREIXÊDAS, V.M. Trilhas: como facilitar a seleção de pontos interpretativos. Circular Técnica IPEF, Piracicaba, n. 186, set. 1998. 
MARTINS, J.F.C; TEIXEIRA, E.C.; SCHERER, A.L.; TEIXEIRA, E.C.; SAUL, P.F. A. Trilha Integração: integrando estudantes, visitantes e ambientes no Campus da Unisinos, RS. Biodiversidade Pampeana, PUCRS, Uruguaiana, 5(1): 16-19, jul. 2007.

MENDONÇA, R. Educação Ambiental vivencial. In: FERRARO-JUNIOR, L.A. Encontros e caminhos: formação de educadoras(es) ambientais e coletivos educadores. Brasília: MMA, 2007.

MENGHINI, F.B. As trilhas interpretativas como recurso pedagógico: caminhos traçados para a Educação Ambiental. Dissertação de mestrado apresentada ao Programa de Mestrado Acadêmico em Educação da Universidade do Vale do Itajaí. Itajaí-SC 2005, 103p.

MORALES, J. Classificacion de los Medios Interpretativos. In: MOORE, A. Manual para la Capacitación del Personal de Áreas Protegidas. Ed. National Park Service, USA, 1992

NASCIMENTO, C.S. Trilha interpretativa guiada: objeto de estudo na Pousada Vale das Araras, Cavalcante-GO. 2004, 69p. Monografia (Pós-graduação lato sensu em Ecoturismo). Centro de Excelência em Turismo, Universidade de Brasília, Brasília, 2004.

PERALTA, C.H.G. Experimentos Educacionais: eventos heurísticos transdisciplinares em Educação Ambiental. In: RUSCHEINSKY, A. (org). Educação Ambiental: abordagens múltiplas. Porto Alegre: Artmed, 2002.

PRIMACK, R. B.; RODRIGUES, E. Biologia da Conservação. Londrina, 2001, $328 p$.

PROJETO DOCES MATAS. (Grupo Temático de Interpretação Ambiental). Manual de Introdução à Interpretação Ambiental. Belo Horizonte, 2002.

RECH \& CANTO-SILVA. Elaboração de roteiro interpretativo para a Trilha Ecológica Virtual do Parque Natural Morro do Osso, Porto Alegre, RS. Porto Alegre, 2012. Trabalho de Conclusão de Curso (Curso Superior em Gestão Ambiental) - Instituto Federal de Educação, Ciência e Tecnologia do Rio Grande do Sul, Campus Porto Alegre, 2012.

SESTREN-BASTOS, M.C. (Coord.) Plano de Manejo Participativo do Parque Natural Morro do Osso. Porto Alegre: Secretaria Municipal do Meio Ambiente, 2006. Disponível em: http://proweb.procempa.com.br/pmpa/prefpoa/smam/usu doc/plano de manej o morro do osso com anexos.pdf. Acesso em: 23 de maio de 2017.

SILVA, R.F. Identificação das oportunidades pedagógicas da Trilha de Educação Ambiental do Parque Natural Morro do Osso. Trabalho de conclusão submetido ao Curso de Graduação em Ciências da Natureza do Instituto Federal de Educação, Ciência e Tecnologia do Rio Grande do Sul, como requisito parcial para obtenção do título Licenciatura em Biologia e Química. Porto Alegre, 2015. 
SILVA, D.M.; JÚNIOR, A.L. A relação entre trilhas interpretativas, Interpretação Ambiental e Educação Ambiental, e a importância das espécies arbóreas para essas atividades. Anais do II Simpósio Nacional de Ensino de Ciência e Tecnologia. 07 a 09 de outubro de 2010.

TILDEN, F. Selecciones de "Interpretando Nuestra Herencia". Turrialba, Costa Rica: CATIE, 1977.

VASCONCELLOS, J.M.O. Trilhas interpretativas: aliando educação e recreação. In: Congresso Brasileiro de Unidades de Conservação, 1., 1997, Curitiba. Anais. Curitiba: IAP, UNILIVRE, REDE PRÓ-UC, 1997, v.1, p.465477.

VASCONCELLOS, J. M. O. Avaliação da visitação pública e da eficiência de diferentes tipos de trilhas interpretativas no Parque Estadual Pico do Marumbi e Reserva Natural Salto Morato. Tese apresentada como requisito parcial à obtenção do grau de Doutor em Ciências Florestais. Curso de Pós-Graduaçâo em Engenharia Florestal, Setor de Ciências Agrárias, Universidade Federal do Paraná, Curitiba, 1998.

VASCONCELLOS, J. M. O. Educação e Interpretação Ambiental em Unidades de Conservação. Fundação O Boticário de Proteção à Natureza. Cadernos de Conservação, ano 3, no 4, 2006.

WILSON, E. O futuro da vida: um estudo da biosfera para a proteção de todas as espécies, inclusive a humana. Campus, Rio de Janeiro, 2002, 242p. 